\title{
Retinoic Acid Attenuates the Mild Hyperoxic Lung Injury in Newborn Mice
}

\section{ZIMOVÁ-HERKNEROVÁ, J. MYSLIVEČEK ${ }^{1}$, P. POTMĚŠIL ${ }^{2}$}

Neonatological Department of General Faculty Hospital, Prague, ${ }^{1}$ Institute of Physiology, First Faculty of Medicine, Charles University, Prague, ${ }^{2}$ Institute of Experimental Medicine, Department of Immunopharmacology, Academy of Sciences of the Czech Republic, Prague, Czech Republic

Received April 7, 2005

Accepted January 2, 2007

On-line available January 2, 2007

\begin{abstract}
Summary
Neonatal exposure to hyperoxia alters lung development in mice. We tested if retinoic acid (RA) treatment is capable to affect lung development after hyperoxic injury and to maintain structural integrity of lung. The gene of vascular endothelial growth factor A (VEGF-A) is one of the RA-responsive genes. Newborn BALB/C mice were exposed to room air, $40 \%$ or $80 \%$ hyperoxia for 7 days. One half of animals in each group received $500 \mathrm{mg} / \mathrm{kg}$ retinoic acid from day 3 to day 7 of the experiment. At the end of experiment we assessed body weight (BW), lung wet weight (LW), the wet-to-dry lung weight ratio (W/D) and the expression of mRNA for VEGF-A and G3PDH genes. On day 7 the hyperoxiaexposed sham-treated mice (group 80 ) weighed $20 \%$ less than the room air-exposed group, whereas the $80 \%$ hyperoxic group treated with RA weighed only $13 \%$ less than the normoxic group. W/D values in 80 and $80 \mathrm{~A}$ groups did not differ, although they both differed from the control group and from 40 groups. There was a significant difference between 40 and $40 \mathrm{~A}$ groups, but the control group was different from 40 group but not from $40 \mathrm{~A}$ groups. The 80 and $80 \mathrm{~A}$ groups had mRNA VEGF-A expression lowered to $64 \%$ and $41 \%$ of the control group. RA treatment of normoxic and mild hyperoxic groups increased mRNA VEGF-A expression by about $50 \%$. We conclude that the retinoic acid treatment of newborn BALB/c mice exposed for 7 days to $80 \%$ hyperoxia reduced the growth retardation in the $80 \%$ hyperoxic group, reduced the W/D ratio in the $40 \%$ but not in the $80 \%$ hyperoxic group. Higher VEGF-A mRNA expression in the $80 \%$ hyperoxic group treated with RA was not significant compared to the $80 \%$ hyperoxic group.
\end{abstract}

\section{Key words}

Retinoic acid • Hyperoxia • Vascular endothelial growth factor • Lung injury • Newborn mice

\section{Corresponding author}

M. Zimová-Herknerová, Dept. of Neonatology, Apolinářská 18, 12000 Praha 2, Czech Republic. E-mail: MagdalenaZ@seznam.cz

\section{Introduction}

In our experiment, we exposed newborn mice to two degrees of hyperoxia ( $40 \%$ or $80 \%$ ) and one half of them was treated with the retinoic acid. Neonatal response to hyperoxia is unique, because injury occurs during the period of alveolar development in mice. The newborn mouse is particularly well suited for studies of neonatal oxygen injury. Murine alveolar development begins on postnatal day 3, and saccular division is completed by the 14th postnatal day (Amy et al. 1977). This postnatal period and the relative timing of alveolarization resembles human lung development (Warner et al. 1998).

The pathophysiology of lung injury during oxygen exposure is thought to include direct endothelial and epithelial cell damage by an increase in reactive oxygen species as well as release of products from activated leukocytes accumulating within the lung. Pathological effects of pulmonary oxygen toxicity include: atelectasis, edema, fibrin formation, inflammation, arterial thickening, bronchitis, alveolar cell hypertrophy. A unique feature of the neonatal response to hyperoxia is the diminished alveolar development.

Experiments in rodents showed that exogenous retinoic acid (RA) induces the formation of extra alveoli in newborn rats and maintains alveolar forming ability under inhibiting conditions such as hyperoxia (Massaro and Massaro 1996, Veness-Meehan et al. 2002). Alveolar regeneration induced by $\mathrm{RA}$ may be an important novel therapeutic appproach to the treatment of respiratory diseases characterized by a reduced gas-exchanging 
surface area such as bronchopulmonary dysplasia and emphysema for which there are currently no treatments (Massaro and Massaro 2003).

Retinoids acting through their specific nuclear receptors function as regulators of gene transcription. The genes of VEGF family are RA responsive genes. VEGF family of growth factors plays an essential role in both physiological and pathological angiogenesis. VEGF-A is the best characterized member of the VEGF family. VEGF family of growth factors plays an essential role in both physiological and pathological angiogenesis (Chinoy et al. 2002). Retinoids acting through ther specific nuclear receptors function as regulators of gene transcription (Chinoy et al. 2000).

VEGF-A, which is a mitogen for endothelial cells and is expressed by alveolar epithelial cells, plays an important role in normal lung development and adaptation. VEGF-A gene expression is regulated by oxygen levels (Maniscalco et al. 1997). Chronic hypoxia has been shown to increase the expression of VEGF-A and its receptors VEGFR-1 and VEGFR-2 in the rat lung (Louzier et al. 2003). Since its original description, VEGF has been shown to have effects on a variety of non-endothelial cells, including alveolar epithelial cells (Charnock-Jones 2005).

The links between RA and VEGF pathway are not yet completely understood. However, Massaro and his co-workers hypothesized that RA prevents the downregulation of VEGFR-2, which is associated with a block in angiogenesis and an inhibition of alveolar septation (Clerch et al. 2004).

The first aim of our study was to examine the effect of two degrees ( $40 \%$ or $80 \%$ ) of hyperoxia on body growth, lung injury and on the VEGF-A mRNA expression in newborn mice. The second aim of our experiment was to compare these results between groups that received retinoic acid as a potential therapeutic agent and the other groups, which received placebo.

\section{Methods}

\section{Animals and oxygen exposure protocol}

The time-dated pregnant $\mathrm{BALB} / \mathrm{c}$ mice were maintained on standard laboratory food and water ad libitum. Light was set on from 6:00 to 18:00 h, temperature was kept at $28-30{ }^{\circ} \mathrm{C}$ to achieve a thermoneutral environment. Mice were kept in groups of one adult mother with 9-13 pups. The exposure to $40 \%$ or $80 \%$ oxygen was performed in Plexiglass chambers (space of $1 \mathrm{~m}^{3}$ ), which contained lime soda and oxygen was continuously delivered. The oxygen monitor (MiniOX ${ }^{\circledR} 3000$, MSA, USA) was set to tolerate $5 \%$ deviation of desired oxygen concentration. The oxygen delivered to adult mothers and newborn pups was heated to a temperature $37-39{ }^{\circ} \mathrm{C}$ and humidified to $>70 \%$ relative humidity (humidifier Pegasus, UniNEB, USA). In normobaric hyperoxia, there is slightly less oxygen toxicity under conditions of humidified environment ( $>60 \%$ relative humidity) compared to dry gas oxygen exposure. Pulmonary oxygen toxicity, estimated by wetto-dry weight ratio was less severe in a humid than in a dry atmosphere with normobaric oxygen ( $\operatorname{Lin}$ and Jamieson 1993). Exposure of rats to dry normobaric oxygen caused epithelial thickening in the lobar bronchi, which was not the case with humidified oxygen (Murchie et al. 1993).

\section{Exposure to hyperoxia}

Neonatal BALB/c mice were exposed to hyperoxia. The oxygen was obtained from Linde Technoplyn (Prague, Czech Republic). Within $12 \mathrm{~h}$ of birth, pups from four to eight litters were pooled before being randomly distributed to newly delivered mothers.

The animals were divided into six groups: 1) room air without application of vitamin A $(21), 2)$ room air with application of vitamin A (21A), 3) $40 \%$ oxygen without application of vitamin A (40), 4) $40 \%$ oxygen with application of vitamin A (40A), 5) $80 \%$ oxygen without application of vitamin A (80), and 6) $80 \%$ oxygen with application of vitamin A (80A). Nursing mothers were rotated between all groups every $24 \mathrm{~h}$ to avoid oxygen toxicity in the mothers and to eliminate maternal effects between groups.

\section{Application of vitamin A}

Axetocal inj. (B) (Biotika, retinoic acid) was administered intraperitoneally in the dose $500 \mathrm{mg} / \mathrm{kg}$ once a day from day 3 to day 7 to the following three groups: 21A, 40A, 80A. Veness-Meehan et al. (2002) treated newborn Sprague-Dawley rats with this dose of retinoic acid and found enhanced septal formation after 4 weeks of recovery.

This dose for a puppy of $4 \mathrm{~g}$ body weight represents $2 \mathrm{mg}$ (2940 IU) dose intraperitoneally per day. The $500 \mathrm{mg} / \mathrm{kg}$ dose $(735 \mathrm{k} \mathrm{IU} / \mathrm{kg})$ is the highest dose of vitamin A used in the experiments with animal models of bronchopulmonary dysplasia which does not exert any adverse or toxic events and keeps the mouse puppies 
alive. The adverse or toxic events include lethargy, vomiting, pallor, extremity tenderness, dry or scaly skin, or unusual pigmentation. We observed no adversed events of vitamin A treatment during our experiment. The animals were weighed every day. The other groups of animals received placebo (cottonseed oil diluent) in the same amount. On the day 7 of the experiment, all animals were killed by decapitation. All protocols were approved by the Institutional Ethics Committee.

\section{Lung wet weight/dry weight ratio (W/D)}

The wet-to-dry lung weight ratio represents the measurement of extravascular lung water. The lungs were excised, blotted dry, and weighed to obtain wet weight. The lungs were then dried in an oven at $60{ }^{\circ} \mathrm{C}$ and weighed daily. After $48 \mathrm{~h}$, no further change in weight was observed in any sample. This weight was taken as dry weight for calculation of the wet weight/dry weight ratio (Dhingra et al. 2001).

\section{Lung histology}

After the mice had been killed, lungs were fixed in situ with $4 \%$ paraformaldehyde in phosphate-buffered saline ( $\mathrm{pH}$ 7.4). Tracheas were cannulated and paraformaldehyde was instilled at $25 \mathrm{~cm} \mathrm{H}_{2} \mathrm{O}$ pressure. After $5 \mathrm{~min}$, lungs were removed and further fixed overnight in $4 \%$ paraformaldehyde. On the next day, lungs were washed in PBS and serially dehydrated in increasing concentrations of ethanol before embedding in paraffin. Tissue sections $(5 \mu \mathrm{m})$ were stained with hematoxylin and eosin.

\section{Reverse transcriptase-polymerase chain reaction}

The expression of mRNA of vascular endothelial growth factor A (VEGF-A) was assessed by semiquantitative reverse transcriptase polymerase chain reaction. Total RNA was isolated from approximately $100 \mathrm{mg}$ of lung tissue using the acid guanidinium thiocyanate-phenol-chloroform method (Chomczynski and Sacchi 1987). The yield and purity of RNA was quantified by measuring the ratio of the optical density at 260 and $280 \mathrm{~nm}$. $0.5 \mu \mathrm{g}$ of RNA was then reversely transcribed to complementary DNA (cDNA). cDNA was synthetized using oligo 3 ' primer of VEGF-A and recombinant Moloney murine leukemia virus reverse transcriptase in the presence of RNAse inhibitor and then amplified by PCR.

Following reverse transcription, cDNA was amplified by the polymerase chain reaction with primers for VEGF-A and G3PDH, a housekeeping gene. Both reverse transcription and polymerase chain reaction were performed using the Thermocycler personal combi (Biometra, Germany). PCR reactions were performed with sequence-specific oligonucleotide primers for mouse VEGF-A (forward primer 5'-ACA TCT TCA AGC CGT CCT GTG TGC-3', reverse primer 5'-AAA TGG CGA ATC CAG TCC CAC GAG-3'). Primers for G3PDH, a reporter mRNA, were 5'-CCC ATC ACC ATC TTC CAG-3' and 5'-ATG ACC TTG CCC ACA GCC-3'. The $\mathrm{PCR}$ reaction mix contained the forward and reverse primers $(0.2 \mu \mathrm{M}$ each), dNTPs $(0.2 \mathrm{mM}$ each), $10 \mathrm{mM}$ Tris- $\mathrm{HCl} \mathrm{pH} 8.8,50 \mathrm{mM} \mathrm{KCl}, 1.5 \mathrm{mM} \mathrm{MgCl}_{2}, 1 \mathrm{U}$ of Taq DNA polymerase and $10 \mu \mathrm{l}$ of cDNA in a total reaction volume of $50 \mu \mathrm{l}$. The reagents for the PCR reaction were obtained from Top-Bio (Prague, Czech Republic). The primers for VEGF-A and G3PDH were designed and produced by Biogen (Prague, Czech Republic). Thirty cycles were used for the PCR for VEGF-A gene as well as for the house keeping gene, G3PDH, according to the instruction of Biogen. The cycling temperatures and timings for VEGF-A gene were: $94{ }^{\circ} \mathrm{C}$ for $60 \mathrm{~s}, 62{ }^{\circ} \mathrm{C}$ for $90 \mathrm{~s}$, and $72{ }^{\circ} \mathrm{C}$ for $60 \mathrm{~s}$. The cycling temperatures and timings for G3PDH gene were: $94{ }^{\circ} \mathrm{C}$ for $45 \mathrm{~s}, 60{ }^{\circ} \mathrm{C}$ for $45 \mathrm{~s}$, and $72{ }^{\circ} \mathrm{C}$ for $60 \mathrm{~s}$. After the last cycle, final extension was carried out at $72{ }^{\circ} \mathrm{C}$ for $7 \mathrm{~min}$.

The PCR products 563bp VEGF-A mRNA and 780bp G3PDH, a reporter mRNA, were identified by electrophoresis on $1.5 \%$ agarose gel containing ethidium bromide. Only the samples with the positive expression of the housekeeping gene, G3PDH, were taken for further analysis. The gels were photographed in UV light and software BioDoc II digital (Biometra) was used for densitometric analysis of the bands. The expression of the G3PDH mRNA was constant in all groups and the results of densitometric units of VEGF-A mRNA were counted as VEGF-A/G3PDH ratio.

\section{Statistical analysis}

The data are expressed as mean $\pm \mathrm{SD}$. Two-way ANOVA with repetition was used to compare the six experimental groups. When multiple comparisons were made between means of two experimental groups, Bonferroni's modification of t-test was applied to assess the adequately altered level of significance.

The ratio of mRNA expression of VEGF-A in the normoxic sham-treated mice to the average G3PDH expression mRNA was defined as $100 \%$ (group 21 was taken as control group) and all other groups were 
Table 1. Body weight (BW), lung wet weight (LW), wet/dry weight ratio (W/D), OD mRNA of VEGF-A assessed by RT-PCR and the VEGF-A/G3PDH ratio in 7-day-old mice of particular groups.

\begin{tabular}{lllllll}
\hline Group & $\mathbf{2 1}$ & $\mathbf{2 1 A}$ & $\mathbf{4 0}$ & $\mathbf{4 0 A}$ & $\mathbf{8 0}$ & $\mathbf{8 0 A}$ \\
\hline Number & 10 & 10 & 10 & 10 & 10 & 10 \\
$B W(g)$ day 7 & $4.65 \pm 0.15$ & $4.57 \pm 0.20$ & $4.7 \pm 0.18$ & $4.60 \pm 0.21$ & $3.67 \pm 0.26^{*}$ & $3.98 \pm 0.15$ \\
$L W(m g)$ & $61.7 \pm 1.8$ & $63.7 \pm 2.6$ & $70.3 \pm 2.7$ & $65.6 \pm 1.8$ & $93.6 \pm 1.5$ & $79.9 \pm 0.8$ \\
$W / D$ & $3.88 \pm 0.09$ & $3.93 \pm 0.11$ & $4.12 \pm 0.10^{*}$ & $3.91 \pm 0.04$ & $4.60 \pm 0.09$ & $4.37 \pm 0.20$ \\
$V E G F-A$ mRNA $(O D)$ & $244 \pm 58.4$ & $319 \pm 40.0$ & $238 \pm 24.0^{*}$ & $349 \pm 32.4$ & $94 \pm 12.4$ & $138 \pm 22.7$ \\
$V E G F-A / G 3 P D H$ & 0.48 & 0.64 & 0.47 & 0.70 & 0.20 & 0.30 \\
\hline
\end{tabular}

Data are shown as mean \pm S.D. ${ }^{*} p<0.0083$ in Bonferroni's comparison with control group (21) and respective RA-treated group kept at the same oxygen level.

Table 2. The statistical analysis of particular studied parameters by two-way ANOVA with repetition.

\begin{tabular}{llll}
\hline Parameter & Vitamin A treatment & Concentration of inhaled oxygen & Interaction of two factors \\
\hline$B W$ & 0.31 & $8.23 \mathrm{E}-19$ & 0.007 \\
$L W$ & $3.38 \mathrm{E}-14$ & $5.33 \mathrm{E}-19$ & $5.37 \mathrm{E}-16$ \\
$W / D$ & 0.602 & $5.16 \mathrm{E}-16$ & $5.09 \mathrm{E}-05$ \\
$V E G F-A m R N A$ & $5.42 \mathrm{E}-11$ & $1.46 \mathrm{E}-22$ & 0.018 \\
\hline
\end{tabular}

Presented data are $p$ values of the two-way ANOVA analysis with repetition

presented as a percentage of this group (Fig. 6).

\section{Results}

Survival, growth, lung weight and W/D ratio in neonatal mice exposed to normoxia, $40 \%$ or $80 \%$ hyperoxia which were treated or untreated with vitamin $A$

All newborn mice survived for 7 days in various degrees of hyperoxia, one adult mother mouse died on the sixth day of the experiment. The body weight of the pups from each group on the seventh day of the experiment is presented in Table 1. Neonatal exposure to $80 \%$ hyperoxia negatively affected body growth. At the end of the experiment, i.e. on the day 7, oxygen-exposed shamtreated mice (group 80 ) had $20 \%$ smaller body weight than the room air-exposed group. However, the $80 \%$ hyperoxic group with the application of retinoic acid weighed only $13 \%$ less than the normoxic group. Both these changes were significantly different from the control group by ANOVA analysis $(\mathrm{P}<0.01)$ as well as by Bonferroni's multiple comparison $(\mathrm{P}<0.0083)$. The 80 and $80 \mathrm{~A}$ groups also differed each from other. Regardless of vitamin A application the mild hyperoxic groups (40\% hyperoxia) did not differ in body weights compared to the normoxic groups and both 40 groups differed from the respective 80 groups in Boferroni's multiple comparison.

After 7 days of the experiment the lung wet weight was highest in the $80 \%$ hyperoxic sham-treated group (Table 1). The ANOVA analysis shows highly significant effects of both factors (RA treatment and hyperoxia) and their combination (Table 2).

W/D ratio according to ANOVA is not different between RA- and sham-treated groups. However, when Bonferroni's multiple comparison was made, we found difference between 40 and $40 \mathrm{~A}$ groups and also the control group was different from 40 group but not from $40 \mathrm{~A}$ group. The 80 and $80 \mathrm{~A}$ groups did not differ, although they both differed from control group and from 40 groups.

\section{Lung histology}

Typical structure of neonatal lung tissue is shown in Figure 1. There was no difference between both normoxic groups 21 and 21A. Only moderate histological changes were observed in mildly hyperoxic sham-treated mice of group 40 (Fig. 2). In contrast, major structural changes were seen in lungs of $80 \%$ hyperoxic sham- 


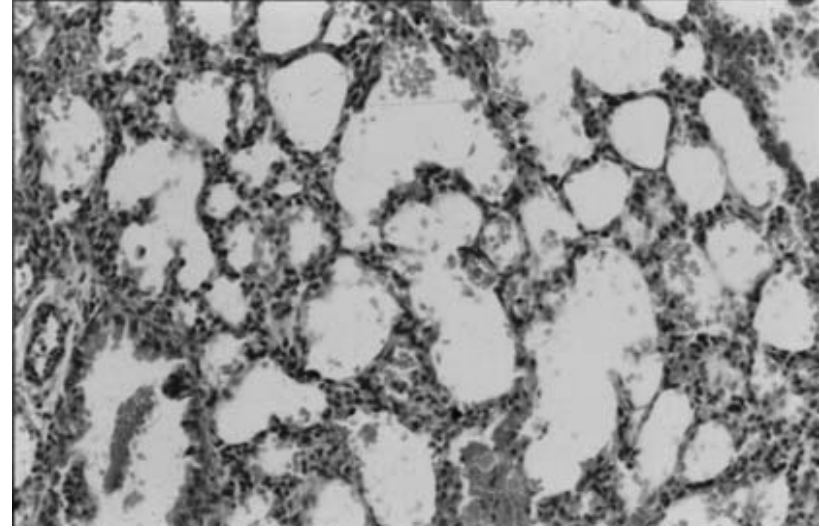

Fig. 1. Typical structure of neonatal mouse lungs with narrow alveolar walls and interalveolar septa and adequate secondary septation (normoxic groups).

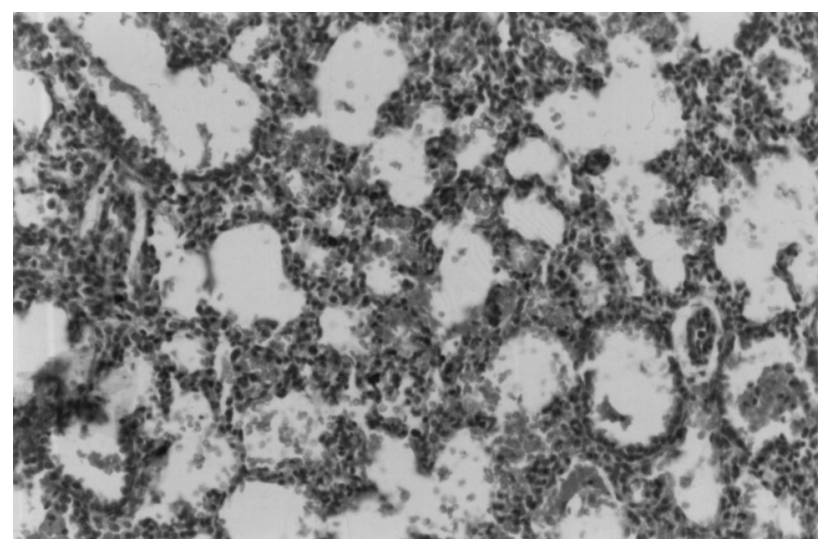

Fig. 2. Lung morphology in the mildly hyperoxic sham-treated mice (group 40). Lung tissue with thickened alveolar walls and interalveolar septa. No alveolar simplification, adequate secondary septation. Some degree of pulmonary interstitial edema.

treated mice (group 80) (Fig. 3). The histological alterations were attenuated in the lungs $80 \%$ hyperoxic mice treated with vitamin A (group 80A) (Fig. 4).

\section{Analysis of the mRNA VEGF expression}

The densitometrical analysis of the RT PCR bands assessed by the software BioDoc II digital (Biometra) is shown in Table 1 . The normoxic and mild hyperoxic RA-treated groups had the expression by $50 \%$ higher than the normoxic sham-treated group. There was no decrease of the mRNA VEGF-A in the $40 \%$ hyperoxic sham-treated group at the end of our experiment. The 80A group had the expression of mRNA VEGF equal to $64 \%$ of the control group. The decrease of VEGF-A mRNA expression in the $80 \%$ hyperoxic sham-treated group was to $41 \%$ of the control group.

ANOVA analysis supported the important role

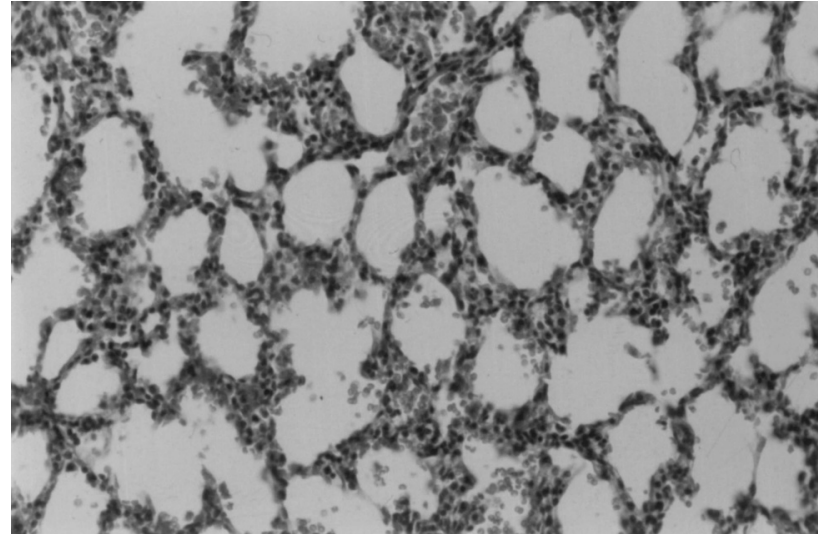

Fig. 3. Lung morphology in the $80 \%$ hyperoxic sham-treated mice (group 80). Lung tissue with enlarged air spaces, thickened alveolar walls and a few secondary crests. Inflammatory cells present in alveoli, interstitial pulmonary edema. Hyaline membranes present focally, squamous epithel metaplasia in bronchi.

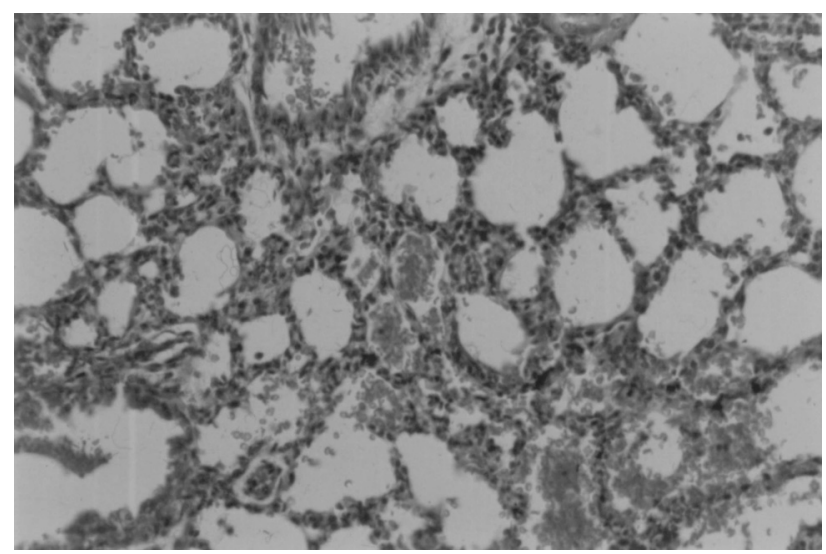

Fig. 4. Lung morphology in the $80 \%$ hyperoxic vitamin Atreated mice (group 80A). Lung tissue with narrow alveolar walls and septa, adequate formation of secondary crests. Inflammatory cells present in alveoli, interstitial pulmonary edema.

of vitamin $\mathrm{A}$ in the VEGF-A gene regulation. However, multiple comparison of these data did not reveal a significant difference between 80 and $80 \mathrm{~A}$ groups, although they both differed from all other groups. On the other hand, VEGF-A gene seems to be vitamin Aresponsive gene. We found significant difference of $40 \mathrm{~A}$ and $21 \mathrm{~A}$ groups from 40 and 21 groups.

\section{Discussion}

In this experiment, we tested whether retinoic acid could act as a useful agent in preventing the hyperoxic injury of the developing lung. We exposed the animals to $40 \%$ or $80 \%$ normobaric hyperoxia for 7 days in order to describe the difference between these two 


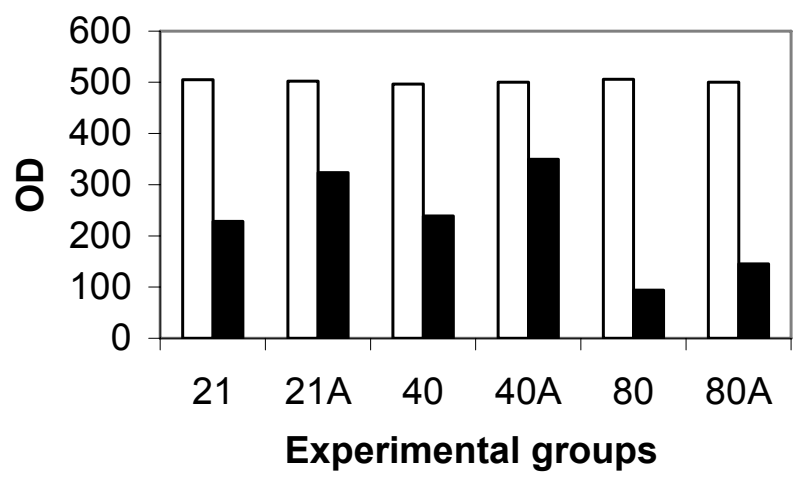

Fig. 5. Expression of mRNA VEGF and G3PDH, a housekeeping gene, in different experimental groups. OD - optical density. Open columns - G3PDH. Full columns - VEGF-A.

hyperoxic injuries as well as the different action of RA in mild or severe hyperoxia. The expression of the mRNA VEGF-A was measured by RT-PCR to identify whether retinoic acid can protect the developing lung from the hyperoxic injury by preserving VEGF-A gene expression.

The mechanism by which RA prevents hyperoxia-induced growth inhibition probably interferes with transforming growth factor $\beta$ (TGF $\beta$ ) signalling pathway. There are numerous reports that oxidative stress is associated with the activation of the TGF $\beta$ pathway. TGF $\beta$ is able to inhibit epithelial cell growth in various tissues including lungs (Chinoy 2003). Recent papers suggest that RA antagonizes TGF $\beta$ pathway by reducing TGF $\beta$ receptor expression in hyperoxia-exposed cells. Mild (40 \%) hyperoxia did not affect growth regardless of RA application. We speculate that $40 \%$ hyperoxia is not strong enough to activate TGF $\beta$ signalling pathway.

The adverse effects of $80 \%$ hyperoxia on body growth of the animals reported in this paper are thus in accordance with other recent papers on this topic. Warner et al. (1998) reported $8 \%$ body weight reduction in newborn mice exposed to $85 \%$ hyperoxia for one week. We have observed even more pronounced body weight changes because there was $20 \%$ body weight loss in the $80 \%$ hyperoxic group and $13 \%$ body weight loss in the $80 \%$ hyperoxic group treated with RA compared to the control group. Our results concerning the body weight changes in the 80A group are similar to Warner's results. There were only $60 \%$ surviving animals after the first week in Warner's experiment, which were performed in different mouse strain (FVB/A). The BALB/c mice used in our experiment might be less sensitive to the hyperoxic lung injury.

The lung weight enlargement during hyperoxia is attributed mainly to extravascular (interstitial)

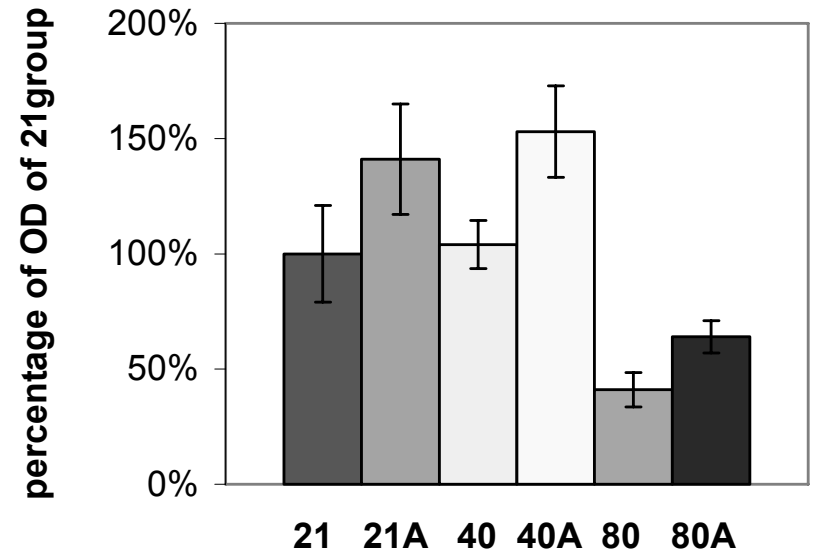

Fig. 6. Percentage of the expression of mRNA VEGF-A in different groups (group $21=100 \%$ )

accumulation of water, sodium and plasma proteins since the cellular mass of pulmonary parenchyma did not increase significantly (Clark and Lambertsen 1971). Our results on lung weight after 7 days of the experiment confirmed lung volume enlargement in all hyperoxic groups. We found significant difference in LW between RA-treated and sham-treated groups. Our histological findings are also in accordance with these principles, since we found pulmonary interstitial edema in all hyperoxic groups except of the 40A group.

The lung weight was also measured by VenessMeehan et al. (2002) who presented the results after 4 weeks of recovery phase from hyperoxia. They reported a $50 \%$ increase in lung weight in the hyperoxic group and smaller elevation of LW in the hyperoxic group treated with RA, the latter effect being not statistically significant compared to the control group. We can only speculate about the importance of this difference between LW between our RA-treated and sham-treated groups measured just after the exposure to hyperoxia. This result might reflect a certain therapeutic effect of RA already during the exposure of hyperoxia.

Our results confirmed the expected increase of W/D ratio in the $80 \%$ hyperoxic group. This increase was detected regardless of the application of vitamin A. Vitamin A did not prevent the edematous lung injury during the exposure to $80 \%$ hyperoxia for one week. According to our results on lung histology and W/D ratio, a mild $(40 \%)$ hyperoxia was also responsible for some degree of lung injury. These results suggest the possibility that retinoic acid might have protective antiedematous effects in $40 \%$ but not in $80 \%$ hyperoxic conditions in the presented design of hyperoxic model.

VEGF-A mRNA expression was significantly 
different in both $80 \%$ hyperoxic groups compared to the normoxic group. The amount of VEGF-A mRNA transcripts was $20 \%$ higher in the $80 \mathrm{~A}$ group than in the 80 group, but this difference was not significant. Thus we have no proof that retinoic acid attenuates the decrease in VEGF-A gene expression under the $80 \%$ hyperoxic conditions. On the other hand, our results in $40 \mathrm{~A}$ and $21 \mathrm{~A}$ group indicate that VEGF-A is a RA-responsive gene. These results are in agreement with other recent papers on this topic. Greater capillary surface density and VEGF-A gene expression were observed in the lungs of preterm lambs receiving retinoic acid under hyperoxic conditions compared to the lungs of untreated lambs (Bland et al. 2000, 2003a,b).

Exogenous provision of RA to explants in whole mouse embryo culture restored vascular remodeling, as well as the signalling pathways that control endothelial growth. Administration of exogenous VEGF-A failed to rescue endothelial cell proliferative control, but promoted vascular remodeling, suggesting that these processess are regulated via a signaling hierarchy downstream of retinoic acid (Bohnsack et al. 2004).

We asked if our results on lung histology, wet lung weight and W/D ratio provide any information about the preserved endothelial cell function. Our results on LW, W/D and VEGF-A mRNA expression obtained in the $80 \%$ hyperoxic group do not enable to draw any general conclusion because the difference in VEGF-A
mRNA expression between RA-treated and sham-treated groups is not significant according to Bonferroni's comparison. We therefore intend to perform further experiments with a longer exposure to $80 \%$ hyperoxia, e.g. two weeks.

\section{Conclusions}

We conclude that the treatment of newborn BALB/c mice exposed for 7 days to $40 \%$ or $80 \%$ hyperoxia with retinoic acid from the 3 rd to the 7 th day of life reduced growth retardation in the $80 \%$ hyperoxic group, decreased W/D ratio in the $40 \%$ but not in the $80 \%$ hyperoxic group and attenuated the decline of the VEGF-A mRNA expression in the $80 \%$ hyperoxic group.

\section{Conflict of Interest}

There is no conflict of interest.

\section{Acknowledgements}

This work was supported by the grant GA UK 6/01 "Hyperoxia in the Pathogenesis of Bronchopulmonary Dysplasia" and was performed as a part of research projects of the Institute of Experimental Medicine AVOZ50390512. The authors thank Jaroslava Rybářová and Veronika Lorincová for their technical assistance and Dr. Mala R. Chinoy for the discussion on this manuscript.

\section{References}

AMY RW, BOWES D, BURRI PH, HAINES J, THORLBECK WM: Postnatal growth of the mouse lung. $J$ Anat 124: 131-151, 1977.

BLAND RD, ALBERTINE KH, CARLTON DP, KULLAMA L, DAVIS P, CHO SC, KIM BI, DAHL M, TABATABAEI A: Chronic lung injury in preterm lambs: abnormalities of the pulmonary circulation and lung fluid balance. Pediatr Res 48: 64-74, 2000.

BLAND RD, ALBERTINE KH, PIERCE RA, STARCHER BC, CARLTON DP: Impaired alveolar development and abnormal lung elastin in preterm lambs with chronic lung injury: potential benefits of retinol treatment. Biol Neonate 84: 101-102, 2003a.

BLAND RD, LING CY, ALBERTINE KH, CARLTON DP, MACRITCHIE AN, DAY RW, DAHL M: Pulmonary vascular dysfunction in preterm lambs with chronic lung disease. Am J Physiol 285: L76-L85, 2003 b.

BOHNSACK BL, LAI L, DOLLE P, HIRSCHI KK: Signaling hierarchy downstream of retinoic acid that independently regulates vascular remodeling and endothelial cell proliferation. Genes Dev 18: 1345-1358, 2004.

CHINOY MR: Lung growth and development. Front Biosci 8: 392-415, 2003.

CHINOY MR, TUDHOPE S, BHABUTA R, CILLEY RE, CHENG ZH, MILLER SA, MYERS RL: Role of retinoic acid and its receptors in murine lung morphogenesis. Am J Respir Crit Care Med 161: A564, 2000.

CHINOY MR, GRAYBILL MM, MILLER SA, LANG CM, KAUFFMAN GL: Angiopoietin-1 and VEGF in vascular development and angiogenesis in hypoplastic lungs. Am J Physiol 283: L60-L66, 2002. 
CHARNOCK-JONES DS: Vascular endothelial growth factors (VEGFs). Their receptors and their inhibition. Celltransmissions 21: 1-7, 2005.

CHOMCZYNSKI P, SACCHI N: Single step method of RNA isolation by acid guanidium thiocyanate-phenolchlorophorm extraction. Anal Biochem 162: 156-159, 1987.

CLARK JM, LAMBERTSEN CJ: Pulmonary oxygen toxicity: a review. Pharmacol Rev 23: 43-48, 1971.

CLERCH LB, BARAS AS, MASSARO GD, HOFFMAN EP, MASSARO D: DNA Microarray analysis of neonatal mouse lung connects regulation of KDR with dexamethasone-induced inhibition of alveolar formation. $A m J$ Physiol 286: L411-L419, 2004.

DHINGRA VK, UUSARO A, HOLMES CL, WALLEY KR: Attenuation of lung inflammation by adrenergic agonists in murine acute lung injury. Anesthesiology 95: 947-953, 2001.

LIN Y, JAMIESON D: Effect of humidity on hyperoxic toxicity. J Appl Physiol 75: 1980-1983, 1993.

LOUZIER V, RAFFESTIN B, LEROUX A, BRANELLEC D, CAILLAUD JM, LEVAME M, EDDAHIBI S, ADNOT S: Role of VEGF-B in the lung during development of chronic hypoxic pulmonary hypertension. Am J Physiol 284: L926-L937, 2003.

MANISCALCO WM, WATKINS RH, DANGIO CT, RYAN RM: Hyperoxic injury decreases alveolar epithelial cell expression of vascular endothelial growth factor (VEGF) in neonatal rabbit lung. Am J Respir Cell Mol Biol 16: 557-567, 1997.

MASSARO D, MASSARO GDC: Postnatal treatment with retinoic acid increases the number of pulmonary alveoli in rats. Am J Physiol 270: L305-L310, 1996.

MASSARO D, MASSARO GDC: Retinoids, alveolus formation, and alveolar defficiency-clinical implications. Am $J$ Respir Cell Mol Biol 28: 271-274, 2003.

MURCHIE P, JOHNSTON PW, ROSS JAS, GODDEN DJ: Effects of hyperoxia on bronchial wall dimensions and lung mechanics in rats. Acta Physiol Scand 148: 363-370, 1993.

VENESS-MEEHAN KA, PIERCE RA, MOATS-STAATS BM, STILES AD: Retinoic acid attenuates $\mathrm{O}_{2}$-induced inhibition of lung septation. Am J Physiol 283: L971-L980, 2002.

WARNER BB, STUART LA, PAPES RA, WISPE JR: Functional and pathological effects of prolonged hyperoxia in neonatal mice. Am J Physiol 275: L110-L117, 1998. 